\title{
Pavlovian determinants of the autoshaped keypeck response
}

\author{
THOMAS PARISI and T. JAMES MATTHEWS \\ New York University, New York, New York 10003
}

\begin{abstract}
Groups of pigeons were autoshaped to peck a key following three pretreatments in which the keypeck was prevented by a barrier which separated the subject from the response key and the hopper. The experimental group (Group PR) received explicit pairings of the keylight and the hopper cues, while the control groups received either a random pairing of the keylight and hopper cues (Group RC) or no stimuli (Group $\mathrm{CH}$ ). Group PR autoshaped most quickly, with Groups $\mathrm{CH}$ and RC following in order. Groups PR and RC were significantly different. This difference was taken as evidence that the Pavlovian pairing operation is central to the acquisition of the autoshaped keypeck response.
\end{abstract}

The principle question raised by the phenomenon of "autoshaping" (Brown \& Jenkins, 1968) is whether the keypeck response is generated by the Pavlovian pairing of the keylight and food reinforcer or by an instrumental contingency where the response is accidentally followed by food. If the former interpretation is correct, there are two major implications for the study of conditioning. The first is that gross skeletal movements of a nonreflexive sort can become Pavlovian conditioned responses. The second implication is that many treatments which were presumed to be instrumental conditioning procedures may now be viewed as Pavlovian procedures. For instance, the operant procedure has imbedded within it a Pavlovian pairing of the presumptive discriminative stimulus and the reinforcer. Thus, it is conceivable that the Pavlovian pairing may be influencing, if not maintaining, the response (Keller, 1974; Rachlin, 1973).

Perhaps the most convincing experiment on this point is Williams and Williams' (1969) application of the omission training procedure. Keypeck responses in the presence of a keylight preclude a food reinforcer which would otherwise occur $6 \mathrm{sec}$ after the onset of the keylight. This design would appear to eliminate the possibility of an accidental instrumental contingency by preventing keypecks from being followed by reinforcement. Further, it establishes a contingency which rewards withholding of the response. Thus, keypecks can only be suppressed by instrumental contingencies whereas the Pavlovian pairing operation would strengthen responding. Because the keypeck response is both maintained and generated by this procedure, the authors infer that the Pavlovian operation is the principle source of the response.

This work was supported by NIMH Grant MH21968-01 awarded to the second author. K:print requests should be sent to T. J. Matthew's, Department of Psychology, New York University, 4 Washington Place. New York. New York 10003. Thomas Parisi is now at the Department of Psychology of the University of Rochester.
However, Wessels (1974) has argued that an accidental instrumental contingency may not be eliminated by this procedure. It is possible that the orienting responses to the key could be accidentally reinforced, since only the keypeck precludes the reinforcer. If the keypeck response is no more than an automatic sequel to the observing response, then it may increase in frequency because the observing response has been accidentally reinforced.

Another strategy for separating the instrumental and Pavlovian contributions to the autoshaped response has been to compare autoshaped responses with reflexive conditioned responses. Jenkins and Moore (1973) autoshaped birds with either food or water as a reinforcer and observed that the form of the autoshaped keypeck resembled the form of the consummatory response elicited by the reinforcer. Thus, it appeared that the principle of "stimulus substitution" which holds for numerous reflexive conditioned responses was also influential in autoshaping.

These data do not allow a strong inference in favor of the Pavlovian interpretation, since Wolin (1968) had previously made the same observation when the reinforcers were explicitly contingent upon the keypeck.

Although the results of these experiments are most easily interpreted as evidence of Pavlovian conditioning, no single experiment is definitive. Since a definitive experiment certainly has and probably always will elude us, we must hope for a convergence among diverse tests of the question. The present experiment represents a familiar approach to this sort of problem (Schoenfeld, Antonitis, \& Bersh, 1950) which has not yet been applied to autoshaping.

The essential Pavlovian operation is the pairing of the keylight and the food. Exposure to these pairings without the opportunity to respond should facilitate subsequent Pavlovian conditioning when keypecks are allowed. This facilitation could not be easily accounted for by accidental instrumental conditioning 


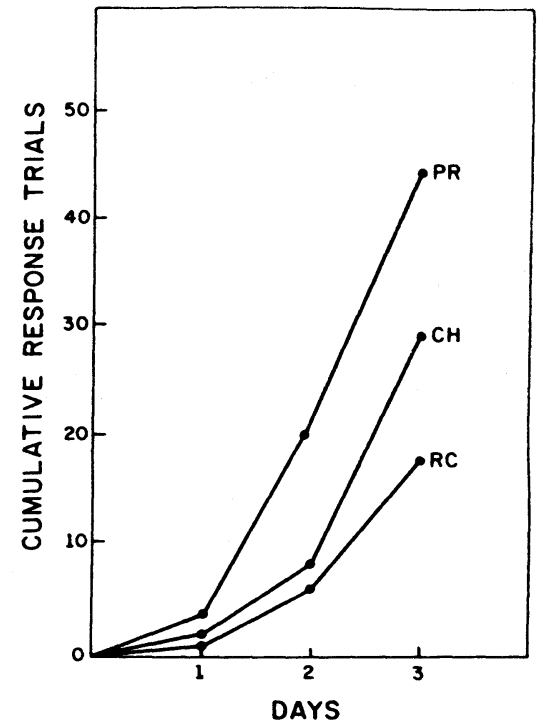

PHASE 3

Figure 1. The mean of the cumulative response trials over the $\mathbf{3}$ days of autoshaping are shown with separate functions for each group. A response trial is a keylight illumination in which one or more responses occur. Group PR received paired keylight and hopper cues, Group RC received randomly presented keylight and hopper cues, and Group $\mathrm{CH}$ received no stimuli.

since responding was prevented during the pairings.

One unusual problem with this experiment involves the effects of "stereotypies" which occur in pigeons exposed to repeated presentations of food (Staddon \& Simmelhag, 1971). These behaviors, if established during magazine training or during the pairings could compete with the subsequent acquisition of the keypeck response. For this reason, magazine training must be conducted with very brief removal of the food. Further, eating cannot be allowed during the pairing operation. Thus, the pairing operation will be between the keylight and the conditioned reinforcers (hopper light and sound) for food established during magazine training.

\section{METHOD}

\section{Subjects}

The subjects were 24 male, experimentally naive, White Carneaux pigeons, deprived to $80 \%$ of their free-feeding weights, which ranged from 400 to $600 \mathrm{~g}$ before the start of the experiment. The pigeons were housed individually and water was continuously available in the home cage.

\section{Apparatus}

The apparatus consisted of a Grason-Stadler standard experimental chamber. A single translucent response key was located above the hopper and could be transillumined with white light. Experimental events were controlled and recorded by an electromechanical switching circuitry and digital recorders.

A transparent acrylic barrier in a wood frame of dimensions $18 \times 18 \times 8 \mathrm{~cm}$ was used in the acquisition phase of the experiment. The barrier rested on the grid floor parallel to the wall on which the keylight and hopper were mounted, at a distance of $3.8 \mathrm{~cm}$. The barrier provided visual access but prevented contact with any part of the front wall of the chamber.

\section{Procedure}

The experiment was divided into four phases: Phase 1 consisted of hopper training for all groups; Phase 2 involved acquisition training; Phases 3 and 4 consisted of tests of acquisition by autoshaping and omission training. During all phases of the experiment, the houselight remained on.

Phase 1. Each pigeon was given hopper training once daily for 4 days. At the start of the first session, the hopper was raised so that the pigeon could eat freely. Once the pigeon began to eat, the hopper was lowered and then presented again after a delay of approximately $20 \mathrm{sec}$. Over the three subsequent sessions, the hopper was raised and lowered three times per session.

Phase 2. In this phase of the experiment, the barrier was set in place in the experimental chamber.

Subjects in Group PR (pairing) received 35 blocked pairings of keylight and hopper. The keylight was illuminated for $7.5 \mathrm{sec}$ and was followed immediately by the hopper for $4 \mathrm{sec}$. These pairings were presented on a VI $60-\mathrm{sec}$ schedule, ranging from $15 \mathrm{sec}$ to $105 \mathrm{sec}$.

Subjects in Group RC (random control) received, on the average, the same number of blocked keylight presentations and blocked hopper presentations as Group PR. However, for Group RC the keylight and hopper were programmed independently of each other, so any pairing that did occur was coincidental (Rescorla, 1968). For this group, the keylight and hopper were presented by separate VI 60 -sec schedules, both ranging from $15 \mathrm{sec}$ to $105 \mathrm{sec}$.

Group $\mathrm{CH}$ (chamber) also served as a control group. Pigeons in this group were placed in the chamber with the transparent barrier in place for $35 \mathrm{~min}$. The keylight and hopper were never presented.

Phase 3. All pigeons in each of the groups then received three daily 30-trial sessions of autoshaping. Again, a 7.5-sec keylight illumination preceded a 4-sec hopper presentation. In this phase the barrier was removed from the chamber and the pairings were presented on the VI 60 -sec schedule.

Phase 4: Omission Training. The omission training procedure was imposed for one 30-trial session with the barrier removed. The procedure was identical to Phase 3 except that keypecks during transillumination cancelled the reinforcer scheduled for that trial. The keylight duration was unaffected by responding.

\section{RESULTS}

The acquisition of the keypeck response in Phase 3 is shown in Figure 1. The mean number of trials on which at least one response occurred (response trials) are plotted cumulatively as a function of the 3 test days. The three groups are shown as separate functions. The mean number of responses for each group was ordered in the same way on each day: Group PR, highest, Group $\mathrm{CH}$, second highest, and Group RC, lowest. The difference between cumulated response trials in Phase 3 for Groups PR and RC was significant [ $t(12)=$ 2.28, $\mathrm{p}<.05$ ], but the PR-CH and CH-RC differences were not significant. It should be noted that one bird in Group PR never learned the keypeck response and was removed from the analysis. Because this exerted a bias against the null hypothesis, the pigeon with the lowest score was deleted from each of the other groups.

The results of Phase 4 showed that the response rate during omission training was a constant proportion of the response rate on the third day of autoshaping. Indeed, for each group the mean response rate during 
the keylight in omission training was $77 \%$ of the mean keylight response rate on the last day of autoshaping.

\section{DISCUSSION}

The rapid acquisition of Group PR relative to Group RC is consistent with the notion that the autoshaped keypeck is under the control of the Pavlovian keylight-food contingency. There are two Pavlovian interpretations of this difference. The faster acquisition by Group PR may indicate that higher order conditioning occurred during the Phase 2 pairings. Alternately, the lower acquisition rate of Group RC may be a kind of "latent inhibition" (Siegal, 1972). During the random presentation, subjects learned a relation that was inhibitory to acquisition of the paired stimuli in Phase 3. This issue might have been decided had Group $\mathrm{CH}$ been reliably different from either Group PR or RC. The former interpretation would have been strengthened had the $\mathrm{PR}$ and $\mathrm{CH}$ groups been distinguishable and the latter would have been confirmed by a significant RC-CH difference. As it was, Group $\mathrm{CH}$ fell between Groups PR and RC.

Although the "higher order conditioning" and "latent inhibition" interpretations cannot be distinguished with these data, the central point survives. Exposure to the Pavlovian pairing operation facilitates acquisition of the autoshaped keypeck relative to the random control. If autoshaped keypecks are, in fact, generated by accidental reinforcement contingencies, there should have been no difference among the groups.

It was disappointing but not surprising that the observed effects of Pavlovian pairing were not stronger. More distinct separations might have been expected had the food reinforcer been presented during the Phase 2 pairings. However, it is well known that the repeated presentation of food generates rigid stereotypies (Staddon \& Simmelhag, 1971). These might have interfered with acquisition of the keypeck. The higher order conditioning procedure was, therefore, preferable even though it could not have been expected to produce a large effect.

These results can be taken as another indication that the autoshaped keypeck arises from the Pavlovian operation as opposed to some accidental instrumental contingency. Since it has so far been impossible to absolutely exclude an instrumental interpretation of experiments intended to distinguish the origins of the autoshaped keypeck, it is encouraging that most results indicate the primacy of the Pavlovian operation.

\section{REFERENCES}

Brown, P. L., \& Jenkins, H. M. Autoshaping of the pigeon's keypeck. Journal of the Experimental Analysis of Behavior, 1968, 11, 1-8.

Jenkins, H. M., \& Moore, B. R. The form of the autoshaped response with food or water reinforcers. Journal of the Experimental Analysis of Behavior, 1973, 20, 163-181.

KELLER, K. The role of elicited responding in behavioral contrast. Journal of the Experimental Analysis of Behavior, 1974, 21, 249-258.

Rachlin, H. Contrast and matching. Psychological Review, 1973. 80, 217-234.

Rescorla, R. A. Probability of shock in the presence and absence of CS in fear conditioning. Joumal of Comparative and Physiological Psychology, 1968, 66, 1-5.

Schoenfeld, W. N., Antonitis, J. J., \& Bersh, P. J. A preliminary study of training conditions necessary for secondary reinforcement. Journal of Experimental Psychology, 1950, 40. $40-45$.

SiegAL, S. Latent inhibition and eyelid conditioning. In A. $\mathrm{H}$. Black and W. F. Prokasy (Eds.), Classical conditioning II: Current research and theory. New York: Appleton-CenturyCrofts, 1972.

Staddon, J. E. R., \& Simmelhag, V. L. The "superstition" experiment: A re-examination of its implications for the principles of adaptive behavior. Psychological Review, 1971, 78. 3-43.

Wessels, M. G. The effects of reinforcement upon the prepecking behavior of pigeons in the autoshaping procedure. Journal of the Experimental Analysis of Behavior, 1974, 21, 125-144.

Williams, D. R., \& Williams, H. Automaintenance in the pigeon: Sustained pecking despite contingent nonreinforcement. Journal of the Experimental Analysis of Behavior, 1969, 12, 511-520.

Wolin, B. R. Difference in manner of pecking a key between pigeons reinforced with food and water. In A. C. Catania (Ed.), Contemporary research in operant behavior. Glenview, Ill: Scott. Foresman, 1968.

(Received for publication August 4, 1975.) 